\title{
EPOS2020: a major step forward
}

Together with this issue of Rhinology, the new European Position Paper on Rhinosinusitis and Nasal Polyps will see the light. The European Position Paper on Rhinosinusitis and Nasal Polyps 2020 is the update of similar evidence based position papers published in 2005, 2007 and $2012^{(1)}$. The core objective of the EPOS2020 guideline is to provide revised, up-to-date and clear evidence-based recommendations and integrated care pathways in ARS and CRS (2). EPOS2020 provides an update on the literature published and studies undertaken in the eight years since the EPOS2012 position paper and addresses areas not extensively covered in EPOS2012 such as paediatric CRS, sinus surgery, exacerbations of CRS ${ }^{(3)}$ and the prevention of CRS ${ }^{(4)}$. EPOS2020 also involves new stakeholders, like neurologists, immunologists, pharmacists and patients and address new target users who have become more involved in the management and treatment of rhinosinusitis since the publication of the last EPOS document, including nurses, specialised care givers and indeed patients themselves, who employ increasing self-management of their condition using over the counter treatments ${ }^{(5,6)}$. The document provides suggestions for future research in this area and offers updated guidance for definitions and outcome measurements for research in different settings. To produce a totally transparent process the EPOS2020 steering group published a development strategy and goals for
EPOS2020 (2). More than 50.000 abstracts have been reviewed and thousands of full text papers analysed. The final result is a 500 page reference work with an executive summary as the first chapter which provides a quick update of what has happened in the last 8 years in rhinosinusitis.

Of course, there is also a very interesting new normal issue of the journal with a paper on dupilumab (Bachert et al, this issue). Dupilumab is the first monoclonal antibody that has been approved for the treatment of CRSwNP by the FDA and EMA. The indication for this expensive treatment (in Europe around $15.000 €$ per year) is now still limited to the very severe patients with CRSWNP (7, EPOS2020). However, one may expect a shift in the treatment of CRSwNP in the coming years ${ }^{(8,9)}$. Also, included in this issue is a paper on a less expensive way to treat patients with CRS by using a new delivery system with fluticasone (Sher et al, this issue). The real power of this new device compared to other delivery forms like nasal sprays and irrigation with nasal corticosteroids still has to take place but the results look very promising. Unfortunately, it is not yet on the market in Europe. A systematic review on endoscopic transnasal orbital decompression for Graves' ophthalmopathy (Tsestos, this issue), papers on $\mathrm{HHT}$, inverted papilloma and smell disorders complete this issue.

\section{References}

1. Fokkens WJ, Lund VJ, Mullol J, Bachert C, Alobid I, Baroody F, et al. European Position Paper on Rhinosinusitis and Nasal Polyps 2012. Rhinol Suppl. 2012;23:3 p preceding table of contents, $1-298$.

2. Fokkens W, Desrosiers M, Harvey R, Hopkins C, Mullol J, Philpott C, et al. EPOS2020: development strategy and goals for the latest European Position Paper on Rhinosinusitis. Rhinology. 2019;57(3):162-8.

3. Phillips KM, Bergmark RW, Hoehle LP, Caradonna DS, Gray ST, Sedaghat AR. Chronic rhinosinusitis exacerbations are differentially associated with lost productivity based on asthma status. Rhinology. 2018;56(4):323-9.

4. Hopkins C, Surda P, Bast F, Hettige R, Walker A, Hellings PW. Prevention of chronic rhinosinusitis. Rhinology. 2018;56(4):307-15.
5. Pugin B, Deneyer L, Bachert C, Alobid I, Bousquet J, De Carlo G, et al. Patient Advisory Board for Chronic Rhinosinusitis - A EUFOREA initiative. Rhinology. 2019;57(5):331-5.

6. Seys SF, Bousquet J, Bachert C, Fokkens WJ, Agache I, Bernal-Sprekelsen M, et al. mySinusitisCoach: patient empowerment in chronic rhinosinusitis using mobile technology. Rhinology. 2018;56(3):209-15.

7. Fokkens WJ, Lund V, Bachert C, Mullol J, Bjermer L, Bousquet J, et al. EUFOREA consensus on biologics for CRSWNP with or without asthma. Allergy. 2019;74(12):2312-9.

8. Tsetsos N, Goudakos JK, Daskalakis D, Konstantinidis I, Markou K. Monoclonal antibodies for the treatment of chronic rhinosinusitis with nasal polyposis: a systematic review. Rhinology. 2018;56(1):11-21.

9. Bidder T, Sahota J, Rennie C, Lund VJ, Robinson DS,
Kariyawasam HH. Omalizumab treats chronic rhinosinusitis with nasal polyps and asthma together-a real life study. Rhinology. 2018;56(1):42-5.

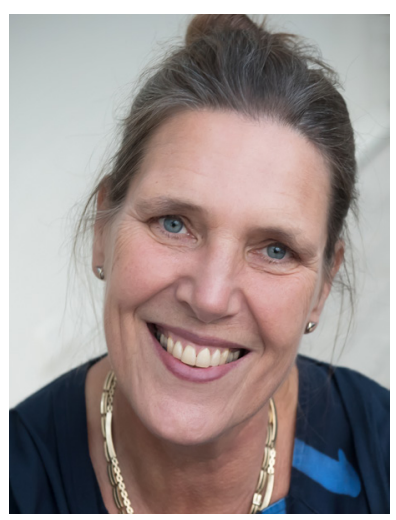

Wytske J. Fokkens, Editor-in Chief Amsterdam, the Netherlands 